\title{
Relationship between non-alcoholic fatty liver disease and periodontal disease: a review and study protocol on the effect of periodontal treatment on non-alcoholic fatty liver disease
}

\begin{abstract}
Chieko Kudo ${ }^{1 *}$, Takaomi Kessoku ${ }^{2}$, Yohei Kamata ${ }^{3}$, Koichi Hidaka ${ }^{1}$, Takeo Kurihashi ${ }^{4}$, Tomoyuki Iwasaki ${ }^{5}$, Shogo Takashiba ${ }^{6}$, Toshiro Kodama $^{7}$, Toshiyuki Tamura ${ }^{3}$, Atsushi Nakajima ${ }^{2}$ and Masato Minabe ${ }^{1}$

${ }^{1}$ Division of Periodontology, Department of Oral Function \& Restoration, Graduate School of Dentistry, Kanagawa Dental University, 82 Inaoka-cho, Yokosuka, Kanagawa 238-8580, Japan

${ }^{2}$ Department of Gastroenterology and Hepatology, Yokohama City University Graduate School of Medicine, 3-9 Fukuura, Kanazawa-ku, Yokohama 236-0004, Japan ${ }^{3}$ Department of Comprehensive Dentistry, Yokohama Clinic, Kanagawa Dental University, 3-31-6 Tsuruya-cho, Kanagawa, Yokohama, Kanagawa 221-0835, Japan ${ }^{4}$ Department of Internal medicine, Yokohama Clinic, Kanagawa Dental University, 3-31-6 Tsuruya-cho, Kanagawa, Yokohama, Kanagawa 221-0835, Japan ${ }^{5}$ Iwasaki Internal Medicine Clinic, 1-1-5 Furu-ruyokohama1F, Kamihoshikawa, Hodogaya-ku Yokohama, Kanagawa 240-0042, Japan

${ }^{6}$ Department of Pathophysiology - Periodontal Science, Okayama University Graduate School of Medicine, Dentistry and Pharmaceutical Sciences, 2-5-1 Shikatacho, Kita-ku, Okayama 700-8525, Japan

${ }^{7}$ Department of Implantology and Periodontology, Graduate School of Dentistry, Kanagawa Dental University, 3-31-6 Tsuruya-cho, Kanagawa, Yokohama, Kanagawa 221-0835, Japan
\end{abstract}

\begin{abstract}
Non-alcoholic fatty liver disease (NAFLD) is a chronic liver disease that is prevalent worldwide. Non-alcoholic steatohepatitis (NASH) is an advanced form of NAFLD and carries the risk of progression from hepatic inflammation and fibrosis to cirrhosis and hepatocellular carcinoma. Pathological mechanisms of NAFLD have been proposed, such as the two-hit hypothesis and the multiple parallel hit hypothesis. Periodontal disease is a chronic infectious disease of the tissues surrounding the teeth that result in tooth loss. Several reports have indicated that periodontal infection is related to NAFLD. NAFLD and periodontal disease are chronic inflammatory conditions that are known as 'silent diseases'. Therefore, both conditions need to be detected early and treated under collaborative medical and dental care in order to prevent progression to NASH. For this purpose, further investigations in humans on the relationship between NAFLD and periodontal disease and on the effect of periodontal treatment on NAFLD are necessary. In this paper, studies on the relationship between NAFLD and periodontal disease are reviewed and a clinical study investigating the effect of periodontal treatment on NAFLD is introduced.
\end{abstract}

\section{Introduction}

Several studies in recent years have reported on the relationship between systemic disease and periodontal disease [1,2]. It has been reported that chronic periodontal disease is related to conditions, such as diabetes mellitus (DM), atherosclerosis and heart disease [3-6]. We have previously reported that infection with periodontal pathogens is associated with the progression of atherosclerosis [7].

Fatty liver disease, which is one of the causes of atherosclerosis $[8,9]$, includes non-alcoholic fatty liver disease (NAFLD) and alcoholic fatty liver disease (AFLD) [10]. NAFLD (in which fat accumulates in the liver without a history of drinking or immune system disease) has gained attention worldwide. NAFLD includes simple steatosis and nonalcoholic steatohepatitis (NASH), which is characterized by a chronic and progressive liver pathology [11]. The prevalence of NAFLD in the American general adult population is $10 \%-40 \%$ and that of NASH is approximately $2 \%-5 \%$ [12].

Recent animal and human investigations have indicated that NAFLD/NASH is related to periodontal disease $[13,14]$. As patients with liver or periodontal disease have few subjective and early symptoms, the diseases are often severe when they are discovered at medical institutions. $[15,16]$. Therefore, early detection and treatment under collaborative medical and dental care is important to prevent progression to NASH, which may then develop into cirrhosis or liver cancer. Further investigations in humans on the relationship between NAFLD and periodontal disease and on the effect of periodontal treatment on NAFLD are desired.

This paper reviews studies on NAFLD and periodontal

*Correspondence to: Dr. Chieko Kudo, DDS, PhD, Lecturer, Division of Periodontology, Department of Oral Function and Restoration, Graduate School of Dentistry, Kanagawa Dental University, 82 Inaoka-cho, Yokosuka, Kanagawa 238-8580, Japan, Tel: +81-46-822-8855; E-mail: kudo@kdu.ac.jp

Key words: non-alcoholic fatty liver disease, periodontal disease, Porphyromonas gingivalis, collaborative medical and dental care

Received: August 15, 2016; Accepted: September 16, 2016; Published: September 20, 2016 
Kudo C (2016) Relationship between non-alcoholic fatty liver disease and periodontal disease: a review and study protocol on the effect of periodontal treatment on non-alcoholic fatty liver disease

disease and briefly introduces our clinical study design: 'A study on the relationship between NAFLD and periodontal disease and on the effect of periodontal disease on NAFLD'. The University hospital Medical Information Network Clinical Trials Registry (UMIN-CTR) identifier is UMIN000022079. NAFLD/NASH and its treatment

NAFLD is a chronic liver disease that occurs in people who drink little or no alcohol and is prevalent worldwide. It is a spectrum of conditions that includes simple steatosis (which has a good prognosis) and NASH. NASH may progress from hepatic inflammation and fibrosis to cirrhosis and hepatocellular carcinoma [17,18]. It has been reported that the main factors for the histological progression of NASH are fibronectin immunohistochemistry, hypertension, diabetes, low-density lipoprotein (LDL) cholesterol and body-mass index (BMI) [19-24]. It is also reported that $67-78 \%$ of individuals with a BMI of 30 or greater have NAFLD $[25,26]$. NAFLD is closely related to DM and metabolic syndrome $[27,28]$. In addition, it has been demonstrated that patients with NAFLD and DM are prone to hepatic inflammation, and the consequent hyperglycaemia, hyperinsulinaemia and hyperlipidaemia promote the progression of atherosclerosis [29].

As a pathological mechanism of NAFLD, the 'two-hit' hypothesis has long been proposed [30]. The 'first hit' is represented by the action of hyperinsulinemia and insulin resistance, accompanying obesity, which leads to liver steatosis and increases the absolute non-esterified fatty acid uptake in the liver and esterification to form triacylglycerol. At the 'second hit', hepato-cytotoxic factors and genetic predisposition lead to progression to NASH [31]. In recent years, a 'multiple parallel hits' hypothesis has been proposed, in which a variety of factors, such as cytokines derived from adipose tissue and the intestinal tract, and dietary factors may play a central role [32]. Multiple hits induce adipokine secretion, endoplasmic reticulum and oxidative stress at the cellular level that subsequently induce hepatic steatosis, inflammation and fibrosis, among which oxidative stress is considered as the major promoter of necroinflammation in NASH through lipid peroxidation $[33,34]$.

General treatment for NASH includes lifestyle modifications such as weight loss through diet and exercise [35]. Pharmacological therapies using agents such as insulin sensitizers, vitamin $\mathrm{E}$ and obeticholic acid are also administered. However, there is still no approved drug for the treatment of NAFLD $[35,36]$.

\section{Periodontal disease and its treatment}

Periodontal disease is an infectious disease of the gums and tissues surrounding the teeth and causes tooth loss due to destruction of tooth-supporting tissues. It has been reported that the incidence rate of periodontitis is over $47 \%$ in adults in the United States of America [37]. More than 700 bacterial species or phylotypes have been detected in the oral cavity [38]. Some species/complexes are closely associated with advanced periodontal lesions, such as Porphyromonas gingivalis (P. gingivalis), Treponema denticola, Tannerella forsythia, Prevotella intermedia, Parvimonas micra, Fusobacterium nucleatum, Eubacterium nodatum and Aggregatibacter actinomycetemcomitans [39,40]. Among them, P. gingivalis, a Gram-negative anaerobic bacterium, is the major aetiological agent that contributes to periodontal disease progression and bone and tissue destruction $[41,42]$. The lipopolysaccharide (LPS) cell-wall component of $P$. gingivalis is one of the virulence factors that trigger a wide range of host responses, including the production of proinflammatory cytokines, anti-inflammatory cytokines and chemokines [43]. These cytokines and inflammatory mediators have important roles in the progression of periodontitis during a stage in which host immune and inflammatory responses lead to the destruction of periodontal tissue under the influence of multiple behavioural, environmental and genetic factors [44].

Recently, the number of studies which demonstrate that chronic periodontal disease (persistent low-grade infection of periodontal pockets by Gram-negative bacteria) is associated with increased $\mathrm{DM}$, atherosclerosis, heart disease, liver cirrhosis and other systemic diseases via the bloodstream has been increasing [3-6]. It has also been suggested that DM and atherosclerosis improve through periodontal treatment [45-55]. Clozza E et al. [56] reported the case of the periodontal management in end-stage liver disease undergoing liver transplantation. At the same time, it has been mentioned that periodontal therapy delivered in close interaction with the referring physicians is important. Hence, it has been proposed that the prevention and management of periodontal disease under collaborative medical and dental care for patients with conditions such as atherosclerosis, DM and liver disease are important [57-63].

The main purpose of periodontal treatment is to control periodontal infection [64]. At first, instruction on the correct way to brush teeth is given to the patient with periodontal disease. Supra- and sub-gingival bacterial plaque/biofilm and calculus are then removed with periodontal scaling and root planning is performed [65].

\section{The relationship between NAFLD and periodontal disease}

Recently, studies on the relationship between NAFLD and periodontal disease have been published.

Research on Japanese university students has suggested that young males with periodontal disease had significantly increased levels of alanine aminotransferase (ALT) [66]. Also, clinical research in healthy Japanese women has demonstrated that the incidence of periodontal disease in females was significantly increased in individuals with elevated serum levels of aspartate aminotransferase (AST), ALT and cholinesterase [67]. Furthermore, it has been reported from an observational study of annual workplace health check-ups at a company in Japan that an association between periodontal disease and the combination of elevated ALT and metabolic syndrome was confirmed in males [68]. It has also been suggested that in Japanese adults with severe periodontal disease and no drinking habit, serum levels of $\gamma$-glutamyl transferase (GGT), a liver biochemical parameter, are high [69].

In vivo study, it was demonstrated that areas of fibrosis with proliferation of hepatic stellate cells and collagen formation were observed in mice with $P$. gingivalis infection that were fed a high fat diet. In addition, it has been reported that in steatotic hepatocytes, expression of toll-like receptor 2 (TLR2), one of the $P$. gingivalis-LPS receptors, was upregulated. $P$. gingivalis-LPS further increased mRNA levels of the palmitate-induced inflammasome and proinflammatory cytokines in steatotic hepatocytes [13]. That is to say, dental infection with $P$. gingivalis exacerbated the pathological progression of NASH from simple steatohepatitis to steatohepatitis with fibrosis through upregulation of the $P$. gingivalis-LPS-TLR2 pathway and activation of inflammasomes. Ilievski $\mathrm{V}$ et al. [70] suggested that biomarkers of oxidative stress in the liver were elevated in mice with periodontitis induced by $P$. gingivalis. Interestingly, Huang $\mathrm{Y}$ et al. reported that periodontitis contributes to adipose tissue inflammation through the nuclear factor-<kappa $>\mathrm{B}$, c-Jun amino-terminal kinase and 
Kudo C (2016) Relationship between non-alcoholic fatty liver disease and periodontal disease: a review and study protocol on the effect of periodontal treatment on non-alcoholic fatty liver disease

extracellular-signal regulated kinase pathways to promote insulin resistance in a rat model [71]. This mechanism by which periodontitis affects the inflammatory response and systemic insulin resistance in the white adipose and liver tissues may be related to the 'first hit' of the two-hit hypothesis which is considered as pathological mechanism of NAFLD. Recently, evidence in mice has shown that disturbance of the composition of gut microbiota by orally derived periodontopathic bacteria such as $P$. gingivalis may be a causal mechanism linking periodontitis and systemic disease including NAFLD [72-74].

Yoneda et al. [14] reported that the detection frequency of $P$. gingivalis in the saliva of patients with NAFLD and NASH was significantly higher than that of non-NAFLD control subjects. In addition, they presented preliminary findings showing that nonsurgical periodontal treatments in 10 patients with NAFLD for 3 months improved liver function parameters such as serum levels of AST and ALT. Taking all of this into account, it is thought that infection with periodontal pathogens mainly composed of $P$. gingivalis is associated with fibrosis severity in patients with NAFLD and that the prevention and eradication of $P$. gingivalis infection through periodontal treatment may have a beneficial effect upon NASH.

We therefore hypothesized that treatment of oral infection, including $P$. gingivalis infection, by periodontal treatment in patients with NAFLD would ameliorate NAFLD-related clinical markers, and we started a clinical study to confirm this under collaborative medical and dental care.

\section{The clinical study design \\ Objectives}

The objectives are to investigate periodontal disease morbidity in patients with NAFLD and to assess the effect of periodontal treatment on NAFLD, under medical and dental collaborative care in Kanagawa Prefecture in Japan.

\section{Study design and outcome measures}

This is a prospective, multicentre, observational, cohort study. Enrolment of participants occurs at four institutes: Yokohama City University Hospital, Kanagawa Dental University Hospital Yokohama Clinic, Kanagawa Dental University Hospital and Iwasaki Internal Medicine Clinic. The study population is ambulatory medical patients and periodontal patients. The former are patients with NAFLD under consultation in the internal medicine or gastroenterology departments who are registered at collaborative investigation facilities, and the latter are patients who have not had treatment at a medical clinic but have been diagnosed as having periodontal disease by the department of periodontics and who are registered at collaborative investigation facilities (Figure 1).

Systemic examinations of fatty liver-related diseases and periodontal examinations will be performed at baseline by the individual physicians and dentists. Relationships between fatty liver-related clinical markers and periodontal clinical markers will be analysed statistically using the examination data. Periodontal treatment including scaling, root planning and instruction in proper home care techniques will be administered to the patients who consent to treatment. During periodontal treatment at the dental institutions, systematic observation will be continued with all patients given nutrition and exercise education at the medical institutions. Individual systemic examination results of fatty liver-related diseases and periodontal examination results will be compared before and after periodontal treatment.
The primary endpoint is ALT level. Secondary outcomes are levels of AST, gamma-glutamyl transpeptidase ( $\gamma \mathrm{GTP})$ and albumin.

\section{Inclusion criteria}

Participant eligibility includes those aged at least 20 years old who have been diagnosed with NAFLD by routine ultrasound in the internal medicine or gastroenterology departments and who have also had a diagnosis of periodontal disease from specialists in periodontal diseases (a periodontal probing depth of $4 \mathrm{~mm}$ or more at any probing site in a periodontal examination).

\section{Exclusion criteria}

Participants will be excluded if they have:

- An alcohol intake of more than $20 \mathrm{~g} /$ day;

- Unstable NAFLD;

- An unstable medication situation;

- Hepatitis C;

- Hepatitis B;

- Autoimmune hepatitis;

- Primary biliary cirrhosis;

- Sclerosis cholangitis;

- Hemochromatosis;

- Alpha-antitrypsin deficiency;

- Wilson disease;

- A history of dental visits within the past 6 months;

- A history of antibiotic use within the past 6 months;

- A history of poor compliance with treatment.

\section{Information collection including lifestyle of participants}

Participants will answer a questionnaire about items such as the following: age, sex, height, weight, systemic history, information about medicines, smoking history, tooth brushing habits and the presence or absence of bruxism.

\section{Systemic examination for fatty liver-related diseases}

Participants will have blood tests and imaging examinations at the medical institutions. The blood test will include white blood count, red blood count, platelet count and levels of triglyceride, high-density lipoprotein cholesterol (HDL-C), LDL-C, AST, ALT, $\gamma$ GTP, albumin, fasting blood glucose, glycosylated haemoglobin (HbA1c) according to the National Glycohemoglobin Standardization Program (NGSP), C-reactive protein (CRP) and high-sensitivity CRP (hs-CRP). The imaging examination will be performed to confirm the presence or absence of fatty liver disease by ultrasonography or FibroScan:

\section{Clinical examination for periodontal disease}

Participants will have the following periodontal examinations at the dental institutions: the amount of $P$. gingivalis in saliva by quantitative polymerase chain reaction (qPCR) and the periodontal disease infection level and severity. The periodontal disease infection level will be determined using a serum immunoglobulin $\mathrm{G}$ (IgG) antibody titre test for $P$. gingivalis FDC381 using an enzyme-linked immunosorbent 
Kudo C (2016) Relationship between non-alcoholic fatty liver disease and periodontal disease: a review and study protocol on the effect of periodontal treatment on non-alcoholic fatty liver disease

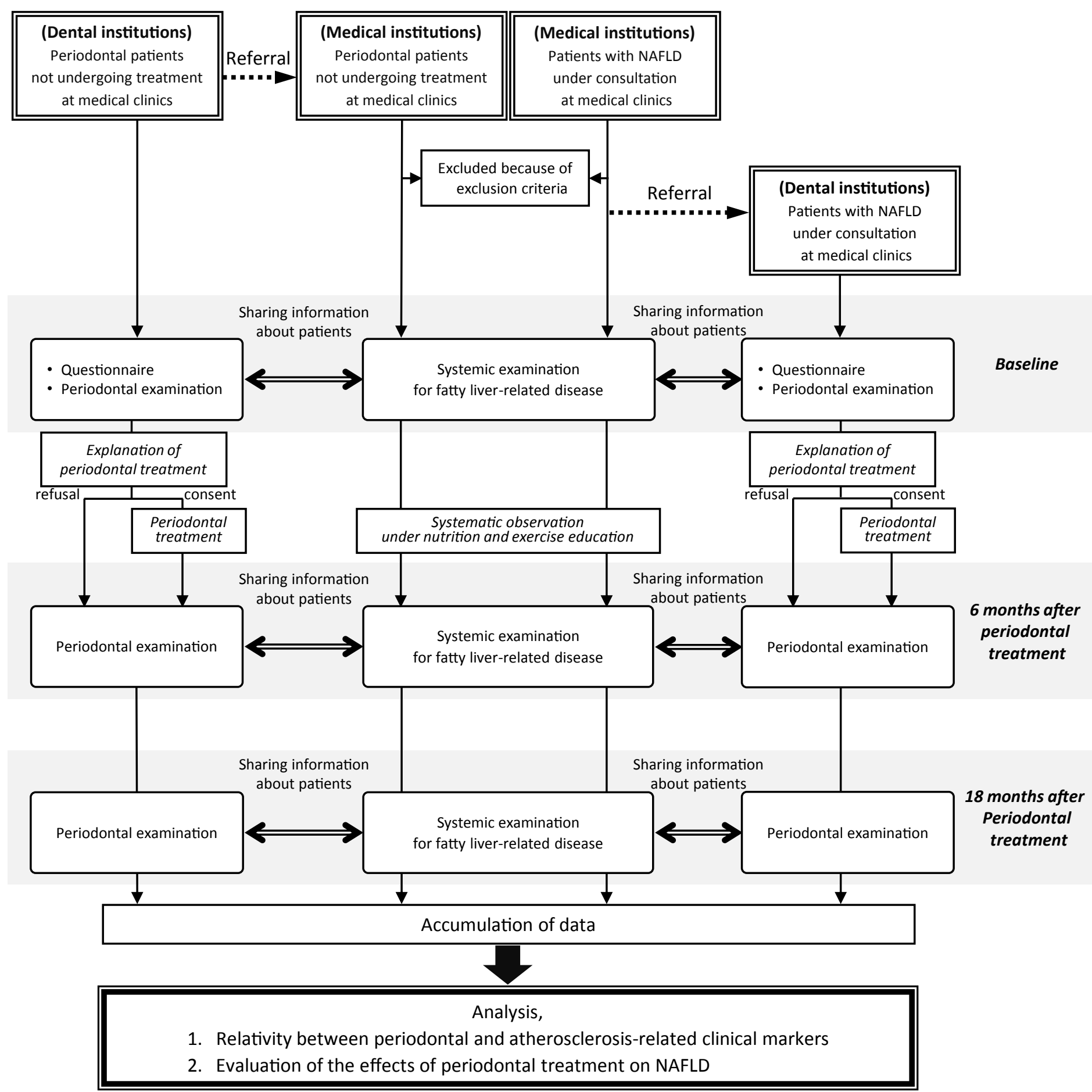

Figure 1. Study flow chart: NAFLD: non-alcoholic fatty liver disease.

assay (ELISA) [75]. Periodontal disease severity will be examined by probing pocket depths, clinical attachment levels, gingival bleedings on probing at six sites per tooth using a calibrated periodontal probe and the stability of the teeth.

\section{Statistical analysis}

The relationship between NAFLD severity (fatty liver-related clinical markers in systemic examinations) and periodontal disease severity (periodontal clinical markers in periodontal examinations) at baseline will be analysed by univariate analysis. In addition, risk factors for NAFLD will be analysed by multivariate analysis using lifestyle factors and fatty liver-related and periodontal clinical markers. Next, the comparison of systemic and periodontal examination results before and after periodontal treatment will be analysed by paired t-test for parametric data and Wilcoxon's signed-rank test for non-parametric data.

\section{Future perspective}

If the study hypothesis is confirmed, periodontal treatment 
Kudo C (2016) Relationship between non-alcoholic fatty liver disease and periodontal disease: a review and study protocol on the effect of periodontal treatment on non-alcoholic fatty liver disease

may contribute to preventing the progression of fibrosis in patients with early NASH and mild fibrosis and to reducing the dose of drug therapy in patients with severe NASH. In future, we will establish an oral infection management system under collaborative medical and dental care to inhibit progression from NAFLD to NASH and aim to contribute to the promotion of good health from the dental side.

\section{Acknowledgments}

This study is supported by a Grant-in-Aid for Scientific Research (C) (No. 16K11872) from the Japan Society for the Promotion of Science.

\section{References}

1. Colombo NH, Shirakashi DJ, Chiba FY, Coutinho MS, Ervolino E, et al. (2012) Periodontal disease decreases insulin sensitivity and insulin signaling. $J$ Periodontol 83: 864-870.[Crossref]

2. Desvarieux M, Demmer RT, Rundek T, Boden-Albala B, Jacobs DR Jr, et al. (2005) Periodontal microbiota and carotid intima-media thickness: the Oral Infections and Vascular Disease Epidemiology Study (INVEST). Circulation 111: 576-582.[Crossref]

3. Tonetti MS, D'Aiuto F, Nibali L, Donald A, Storry C, et al. (2007) Treatment of periodontitis and endothelial function. $N$ Engl J Med 356: 911-920.[Crossref]

4. Beck JD, Eke P, Heiss G, Madianos P, Couper D, et al. (2005) Periodontal disease and coronary heart disease: a reappraisal of the exposure. Circulation 112: 19-24.[Crossref]

5. Michalowicz BS, Hodges JS, DiAngelis AJ, Lupo VR, Novak MJ, et al. (2006) Treatment of periodontal disease and the risk of preterm birth. $N$ Engl J Med 355: 1885-1894.[Crossref]

6. Grønkjær LL (2015) Periodontal disease and liver cirrhosis: A systematic review. SAGE Open Med 3: 2050312115601122.[Crossref]

7. Kudo C, Shin WS, Minabe M, Harai K, et al. (2015) Analysis of the relationship between periodontal disease and atherosclerosis within a local clinical system: a crosssectional observational pilot study. Odontology 103: 314-321.[Crossref]

8. CalzadillaBertot L, Adams LA (2016) The Natural Course of Non-Alcoholic Fatty Liver Disease. Int J Mol Sci 17.[Crossref]

9. Madan SA, John F, Pyrsopoulos N, Pitchumoni CS (2015) Nonalcoholic fatty liver disease and carotid artery atherosclerosis in children and adults: a meta-analysis. Eur J Gastroenterol Hepatol 27: 1237-1248.[Crossref]

10. Sookoian S, Pirola CJ (2013) Systems biology elucidates common pathogenic mechanisms between nonalcoholic and alcoholic-fatty liver disease. PLoS One 8: e58895.[Crossref]

11. Başaranoğlu M, Örmeci N (2014) Nonalcoholic fatty liver disease: diagnosis, pathogenesis, and management. Turk J Gastroenterol 25: 127-132.[Crossref]

12. Maddur H, Neuschwander-Tetri BA (2014) More evidence that probiotics may have a role in treating fatty liver disease. Am J Clin Nutr 99: 425-426.[Crossref]

13. Furusho H, Miyauchi M, Hyogo H, Inubushi T, Ao M, et al. (2013) Dental infection of Porphyromonasgingivalis exacerbates high fat diet-induced steatohepatitis in mice. $J$ Gastroenterol 48: 1259-1270.[Crossref]

14. Yoneda M, Naka S, Nakano K, Wada K, Endo H, et al. (2012) Involvement of a periodontal pathogen, Porphyromonasgingivalis on the pathogenesis of non-alcoholic fatty liver disease. BMC Gastroenterol 12: 16.[Crossref]

15. López-Velázquez JA, Silva-Vidal KV, Ponciano-Rodríguez G, Chávez-Tapia NC, Arrese M, et al. (2014) The prevalence of nonalcoholic fatty liver disease in the Americas. Ann Hepatol 13: 166-178.[Crossref]

16. Cunha-Cruz J, Hujoel PP, Kressin NR (2007) Oral health-related quality of life of periodontal patients. J Periodontal Res 42: 169-176. [Crossref]

17. Neuschwander-Tetri BA, Caldwell SH (2003) Nonalcoholic steatohepatitis: summary of an AASLD Single Topic Conference. Hepatology 37: 1202-1219.[Crossref]

18. Koplay M, Sivri M, Erdogan H, Nayman A (2015) Importance of imaging and recent developments in diagnosis of nonalcoholic fatty liver disease. World J Hepatol 7: 769776.[Crossref]

19. Sorrentino P, D'Angelo S, Ferbo U, Micheli P, Bracigliano A, et al. (2009) Liver iron excess in patients with hepatocellular carcinoma developed on non-alcoholic steatohepatitis. J Hepatol 50: 351-357.[Crossref]
20. Singh S, Allen AM, Wang Z, Prokop LJ, Murad MH, et al. (2015) Fibrosis progression in nonalcoholic fatty liver vs nonalcoholic steatohepatitis: a systematic review and meta-analysis of paired-biopsy studies. ClinGastroenterol Hepatol 13: 643-654. [Crossref]

21. McPherson S, Hardy T, Henderson E, Burt AD, Day CP, et al. (2015) Evidence of NAFLD progression from steatosis to fibrosing-steatohepatitis using paired biopsies: implications for prognosis and clinical management. $J$ Hepatol 62: 1148-1155. [Crossref]

22. Wong VW, Wong GL, Choi PC, Chan AW, Li MK, et al. (2010) Disease progression of non-alcoholic fatty liver disease: a prospective study with paired liver biopsies at 3 years. Gut 59: 969-974.[Crossref]

23. Koruk M, Savaş MC, Yilmaz O, Tayşi S, Karakok M, et al. (2003) Serum lipids, lipoproteins and apolipoproteins levels in patients with nonalcoholic steatohepatitis. $J$ Clin Gastroenterol 37: 177-182.[Crossref]

24. Aller R, Izaola O, Ruiz-Rebollo L, Pacheco D, de Luis DA (2015) Predictive factors of non-alcoholic steatohepatitis: relationship with metabolic syndrome. Nutr Hosp 31: 2496-2502.[Crossref]

25. Houghton-Rahrig LD, Schutte DL, von Eye A, Fenton JI, Given BA, et al. (2013) Exploration of a symptoms experience in people with obesity-related nonalcoholic fatty liver disease. Nurs Outlook 61: 242-251.[Crossref]

26. Williams CD, Stengel J, Asike MI, Torres DM, Shaw J, et al. (2011) Prevalence of nonalcoholic fatty liver disease and nonalcoholic steatohepatitis among a largely middle-aged population utilizing ultrasound and liver biopsy: a prospective study. Gastroenterology 140: 124-131.[Crossref]

27. Zeb I, Katz R, Nasir K, Ding J, Rezaeian P, et al. (2013) Relation of nonalcoholic fatty liver disease to the metabolic syndrome: the Multi-Ethnic Study of Atherosclerosis. $J$ Cardiovasc ComputTomogr 7: 311-318.[Crossref]

28. Al Rifai M, Silverman MG, Nasir K, Budoff MJ, Blankstein R, et al. (2015) The association of nonalcoholic fatty liver disease, obesity, and metabolic syndrome, with systemic inflammation and subclinical atherosclerosis: the Multi-Ethnic Study of Atherosclerosis (MESA). Atherosclerosis 239: 629-633.[Crossref]

29. Xu X, Lu L, Dong Q, Li X, Zhang N, et al. (2015) Research advances in the relationship between nonalcoholic fatty liver disease and atherosclerosis. Lipids Health Dis 14: 158. [Crossref]

30. Day CP, James OF (1998) Steatohepatitis: a tale of two "hits"? Gastroenterology 114: 842-845.[Crossref]

31. Marzuillo P, Grandone A, Perrone L, Miraglia Del Giudice E (2015) Understanding the pathophysiological mechanisms in the pediatric non-alcoholic fatty liver disease: The role of genetics. World J Hepatol 7: 1439-1443.[Crossref]

32. Tilg H, Moschen AR (2010) Evolution of inflammation in nonalcoholic fatty liver disease: the multiple parallel hits hypothesis. Hepatology 52: 1836-1846.[Crossref]

33. Takaki A, Kawai D, Yamamoto K (2013) Multiple hits, including oxidative stress, as pathogenesis and treatment target in non-alcoholic steatohepatitis (NASH). Int J Mol Sci 15: 20704-20728. [Crossref]

34. Köroğlu E, Canbakan B, Atay K, Hatemi İ, Tuncer M, et al. (2016) Role of oxidative stress and insulin resistance in disease severity of non-alcoholic fatty liver disease. Turk J Gastroenterol27: 361-366.[Crossref]

35. Hardy T, Anstee QM, Day CP (2015) Nonalcoholic fatty liver disease: new treatments. Curr Opin Gastroenterol 31: 175-183.[Crossref]

36. Pereira K, Salsamendi J, Casillas J (2015) The Global Nonalcoholic Fatty Liver Disease Epidemic: What a Radiologist Needs to Know. J Clin Imaging Sci 5: 32.[Crossref]

37. Eke PI, Dye BA, Wei L, Thornton-Evans GO, Genco RJ; CDC Periodontal Disease Surveillance workgroup: James Beck (University of North Carolina, et al. (2012) Prevalence of periodontitis in adults in the United States: 2009 and 2010. J Dent Res 91: 914-920.[Crossref]

38. Aas JA, Paster BJ, Stokes LN, Olsen I, Dewhirst FE (2005) Defining the normal bacterial flora of the oral cavity. J Clin Microbiol 43: 5721-5732.[Crossref]

39. Bodet C, Chandad F, Grenier D (2007) Pathogenic potential of Porphyromonasgingivalis, Treponemadenticola and Tannerella forsythia, the red bacterial complex associated with periodontitis. Pathol Biol (Paris) 55: 154-162.[Crossref]

40. Pérez-Chaparro PJ, Gonçalves C, Figueiredo LC, Faveri M, Lobão E, et al. (2014) Newly identified pathogens associated with periodontitis: a systematic review. $J$ Dent Res 93: 846-858.[Crossref]

41. Holt SC, Kesavalu L, Walker S, Genco CA (1999) Virulence factors of 
Kudo C (2016) Relationship between non-alcoholic fatty liver disease and periodontal disease: a review and study protocol on the effect of periodontal treatment on non-alcoholic fatty liver disease

Porphyromonasgingivalis. Periodontol 2000 20: 168-238.[Crossref]

42. How KY, Song KP, Chan KG (2016) Porphyromonasgingivalis: An Overview of Periodontopathic Pathogen below the Gum Line. Front Microbiol 7: 53.[Crossref]

43. Sun Y, Li H, Yang MF, Shu W, Sun MJ, et al. (2012) Effects of aging on endotoxin tolerance induced by lipopolysaccharides derived from Porphyromonasgingivalis and Escherichia coli. PLoS One 7: e39224.[Crossref]

44. Liang S, Krauss JL, Domon H, McIntosh ML, Hosur KB, et al. (2011) The C5a receptor impairs IL-12-dependent clearance of Porphyromonasgingivalis and is required for induction of periodontal bone loss. J Immunol 186: 869-877.[Crossref]

45. Stewart JE, Wager KA, Friedlander AH, Zadeh HH (2001) The effect of periodontal treatment on glycemic control in patients with type 2 diabetes mellitus. $J$ Clin Periodontol 28: 306-310.[Crossref]

46. Rodrigues DC, Taba MJ, Novaes AB, Souza SL, Grisi MF (2003) Effect of non-surgical periodontal therapy on glycemic control in patients with type 2 diabetes mellitus. $J$ Periodontol 74: 1361-1367.[Crossref]

47. Navarro-Sanchez AB, Faria-Almeida R, Bascones-Martinez A (2007) Effect of nonsurgical periodontal therapy on clinical and immunological response and glycaemic control in type 2 diabetic patients with moderate periodontitis. J Clin Periodontol 34: 835-843.[Crossref]

48. Santos VR, Lima JA, De Mendonça AC, BrazMaximo MB, Faveri M, et al. (2009) Effectiveness of full-mouth and partial-mouth scaling and root planing in treating chronic periodontitis in subjects with type 2 diabetes. J Periodontol 80: 1237-1245. [Crossref]

49. Engebretson SP, Hey-Hadavi J (2011) Sub-antimicrobial doxycycline for periodontitis reduces hemoglobin A1c in subjects with type 2 diabetes: a pilot study. Pharmacol Res 64: 624-629.[Crossref]

50. Katagiri S, Nagasawa T, Kobayashi H, Takamatsu H, Bharti P, et al. (2012) Improvement of glycemic control after periodontal treatment by resolving gingival inflammation in type 2 diabetic patients with periodontal disease. $J$ Diabetes Investig 3: 402-409.[Crossref]

51. Santos VR, Lima JA, Miranda TS, Gonçalves TE, Figueiredo LC, et al. (2013) Fullmouth disinfection as a therapeutic protocol for type-2 diabetic subjects with chronic periodontitis: twelve-month clinical outcomes: a randomized controlled clinical trial. $J$ Clin Periodontol 40: 155-162.[Crossref]

52. Munenaga Y; Hiroshima Study Group, Yamashina T, Tanaka J, Nishimura F (2013) Improvement of glycated hemoglobin in Japanese subjects with type 2 diabetes by resolution of periodontal inflammation using adjunct topical antibiotics: results from the Hiroshima Study. Diabetes Res ClinPract 100: 53-60. [Crossref]

53. Artese HP, Foz AM, RabeloMde S, Gomes GH, Orlandi M, et al. (2015) Periodonta therapy and systemic inflammation in type 2 diabetes mellitus: a meta-analysis. PLoS One 10: e0128344.[Crossref]

54. Higashi Y, Goto C, Hidaka T, Soga J, Nakamura S, et al. (2009) Oral infectioninflammatory pathway, periodontitis, is a risk factor for endothelial dysfunction in patients with coronary artery disease. Atherosclerosis 206: 604-610. [Crossref]

55. Higashi Y, Goto C, Jitsuiki D, Umemura T, Nishioka K, et al. (2008) Periodontal infection is associated with endothelial dysfunction in healthy subjects and hypertensive patients. Hypertension 51: 446-453. [Crossref]

56. Clozza E, Segelnick SL, Sigal SH, Rovner DN, Weinberg MA (2016) Periodontal Management of a Patient Undergoing Liver Transplantation. Int J Periodontics Restorative Dent 36: 263-273.[Crossref]

57. Kapellas K, Maple-Brown LJ, Jamieson LM, Do LG, O'Dea K, et al. (2014) Effect of periodontal therapy on arterial structure and function among aboriginal australians: a randomized, controlled trial. Hypertension 64: 702-708.[Crossref]

58. Bal MV, Olgun A, Abaslı D, Özdemir A, Kürşaklıŏlu H, et al. (2014) The effect of nonsurgical periodontal treatment on serum and saliva chitotriosidase activities in patients with periodontitis and coronary artery disease. TherClin Risk Manag 11: 5358. [Crossref]

59. Grubbs V, Vittinghoff E, Beck JD, Kshirsagar AV, et al. (2015) Association Between Periodontal Disease and Kidney Function Decline in African Americans: The Jackson Heart Study. J Periodontol 86: 1126-1132.[Crossref]

60. Botero JE, Yepes FL, Ochoa SP, Hincapie JP, Roldan N, et al. (2013) Effects of periodontal non-surgical therapy plus azithromycin on glycemic control in patients with diabetes: a randomized clinical trial. J Periodontal Res 48: 706-712.[Crossref]

61. Telgi RL, Tandon V, Tangade PS, Tirth A, Kumar S, et al. (2013) Efficacy of nonsurgical periodontal therapy on glycaemic control in type II diabetic patients: a randomized controlled clinical trial. J Periodontal Implant Sci 43: 177-182.[Crossref]

62. Raman RP, Taiyeb-Ali TB, Chan SP, Chinna K, Vaithilingam RD (2014) Effect of nonsurgical periodontal therapy verses oral hygiene instructions on type 2 diabetes subjects with chronic periodontitis: a randomised clinical trial. BMC Oral Health 14: 79.[Crossref]

63. Seshima F, Nishina M, Namba T, Saito A (2016) Periodontal Regenerative Therapy in Patient with Chronic Periodontitis and Type 2 Diabetes Mellitus: A Case Report. Bull Tokyo Dent Coll 57: 97-104.[Crossref]

64. Darby I (2009) Non-surgical management of periodontal disease. Aust Dent J 54 Suppl 1: S86-95.[Crossref]

65. American Academy of Periodontology (2011) Comprehensive periodontal therapy: a statement by the American Academy of Periodontology. J Periodontol 82: 943-949. [Crossref]

66. Furuta M, Ekuni D, Yamamoto T, Irie K, Koyama R, et al. (2010) Relationship between periodontitis and hepatic abnormalities in young adults. Acta Odontol Scand 68: 27-33 [Crossref]

67. Saito T, Shimazaki Y, Koga T, Tsuzuki M, Ohshima A (2006) Relationship between periodontitis and hepatic condition in Japanese women. J Int Acad Periodontol 8: 8995.[Crossref]

68. Ahmad A, Furuta M, Shinagawa T, Takeuchi K, Takeshita T, et al. (2015) Association of periodontal status with liver abnormalities and metabolic syndrome. J Oral Sci 57 335-343.[Crossref]

69. Morita T, Yamazaki Y, Fujiharu C, Ishii T, Seto M, et al. (2014) Serum $\hat{\mathrm{I}}^{3}$ glutamyltransferase level is associated with periodontal disease independent of drinking habits in Japanese adults. Med SciMonit 20: 2109-2116.[Crossref]

70. Ilievski V, Kinchen JM,Prabhu R, Rim F, Leoni L, et al. (2016) Experimenta Periodontitis Results in Prediabetes and Metabolic Alterations in Brain, Liver and Heart: Global Untargeted Metabolomic Analyses. J Oral Biol (Northborough) 3.[Crossref]

71. Huang Y, Zeng J, Chen G, Xie X, Guo W, et al. (2016) Periodontitis contributes to adipose tissue inflammation through the NF-B, JNK and ERK pathways to promote insulin resistance in a rat model. Microbes Infect S1286-4579(16)30104-6.

72. Arimatsu K, Yamada H, Miyazawa H, Minagawa T, Nakajima M, et al. (2014) Oral pathobiont induces systemic inflammation and metabolic changes associated with alteration of gut microbiota. Sci Rep 4: 4828.[Crossref]

73. Nakajima M, Arimatsu K, Kato T, Matsuda Y, Minagawa T, et al. (2015) Oral Administration of $\mathrm{P}$. gingivalis Induces Dysbiosis of Gut Microbiota and Impaired Barrier Function Leading to Dissemination of Enterobacteria to the Liver. PLoS One 10: e0134234.[Crossref]

74. Matsuda Y, Kato T, Takahashi N, Nakajima M, Arimatsu K, et al. (2016) Ligatureinduced periodontitis in mice induces elevated levels of circulating interleukin- 6 but shows only weak effects on adipose and liver tissues. J Periodontal Res 51: 639-646. [Crossref]

75. Kudo C, Naruishi K, Maeda H, Abiko Y, Hino T, et al. (2012) Assessment of the plasma/serum IgG test to screen for periodontitis. J Dent Res 91: 1190-1195.[Crossref]

Copyright: (C2016 Kudo C. This is an open-access article distributed under the terms of the Creative Commons Attribution License, which permits unrestricted use, distribution, and reproduction in any medium, provided the original author and source are credited. 